\title{
FRANQUISMO: PRISIONES Y PRISIONEROS
}

Julián Chaves Palacios

\section{INTRODUCCIÓN}

Tras el Alzamiento de julio de $1936^{1}$, en las zonas controladas por los sublevados los centros de reclusión adquirieron un especial movimiento de presos, debido, por un lado, a la liberación de prisioneros políticos afines, principalmente falangistas, $y$, por otro, a consecuencia del encarcelamiento masivo de republicanos. Esto último provocó, ante el ingente número de presos que ingresaron en prisión y las limitadas dimensiones de las prisiones existentes, el hacinamiento de una población reclusa que no cabía en las cárceles provinciales, ni tampoco en las de cada partido judicial o en los depósitos municipales. Un excedente de reclusos que se trató de combatir con una serie de medidas que, un primer momento, fueron canalizadas a través de la Comisión de Justicia de la Junta Técnica del Estado2.

Pero los problemas de masificación que registraban los centros de reclusión en zona insurgente iban en aumento a medida que transcurrían los primeros meses de guerra y requerían una atención especial por parte de las nuevas autoridades. Eso al menos se desprende de la publicación de medidas como la aprobada el 30 de octubre de 1936, por la que se creaba la Inspección de Presidios y Prisiones que estaba vinculada expresamente a la presidencia de la Junta Técnica ${ }^{3}$ y que tuvo como particularidad ser un cuerpo civil en esencia, aunque dirigido, debido a los condicionamientos inherentes a la situación bélica,

1. Este artículo se inserta dentro de los Proyectos de Investigación financiados por la Junta de Extremadura números: 200017010011 y 2PR02A004.

2. La Junta Técnica del Estado se creó el 1 de octubre de 1936 y la componían siete Comisiones entre las que se incluía la de Justicia, que tenía entre sus competencias las prisiones.

3. Al frente de esa Inspección se puso a Joaquín del Moral y Pérez de Aloe, abogado y escritor madrileño, defensor de los militares sublevados el 10 de agosto de 1932 y amigo personal del general Sanjurjo. Berdugo, I. y otros, "El Ministerio de Justicia en la España Nacional", en AA. VV., Justicia en Guerra, Madrid, Ministerio de Cultura, 1990, p. 258. 
por militares ${ }^{4}$. Y ya en julio de 1937 se daba un nuevo paso en la vertebración penitenciaria con la creación de la Dirección de Prisiones, a la que se dotó de mayores competencias que la Inspección, al completar las funciones de reconocimiento con las de organización, personal y trabajo de los penados.

\section{Legislación penitenciaria republicana derogada en noviembre de 1936}

\begin{tabular}{|c|l|}
\hline Fecha & \multicolumn{1}{|c|}{ Contenido } \\
\hline 24-IV-1931 & $\begin{array}{l}\text { Orden que establecía la libertad de conciencia de los reclusos y la } \\
\text { recepción de prensa }\end{array}$ \\
\hline $12-\mathrm{V}-1931$ & Orden para mejorar el régimen alimenticio de los presos \\
\hline $30-\mathrm{XI}-1931$ & $\begin{array}{l}\text { Circular disponiendo que los gastos de viaje, billetes de ferrocarril y ropa } \\
\text { de penados puestos en libertad serían abonados por la Administración }\end{array}$ \\
\hline $22-\mathrm{III}-1932$ & $\begin{array}{l}\text { Decreto por el que se concedía la libertad condicional a los } \\
\text { septuagenarios de intachable conducta que ofrecieran garantías de llevar } \\
\text { vida honrada en libertad }\end{array}$ \\
\hline $29-\mathrm{III}-1932$ & $\begin{array}{l}\text { Decreto por el que se creaba el Instituto de Estudios Penales destinado a } \\
\text { la preparación del personal de prisiones y a la ampliación de sus estudios }\end{array}$ \\
\hline $27-\mathrm{IX}-1934$ & $\begin{array}{l}\text { Decreto por el que se concedía un suplemento extraordinario para } \\
\text { manutención de internos e hijos de reclusos en su compañía }\end{array}$ \\
\hline $25-\mathrm{X}-1935$ & $\begin{array}{l}\text { Ley que ordenaba la retirada urgente de cadenas blancas, grillos e hierros } \\
\text { de sujeción que aún quedaban en los establecimientos penitenciarios }\end{array}$ \\
\hline
\end{tabular}

A la par que se creaban esos organismos y hasta que se aprobara la nueva legislación procesal y penal en materia de prisiones, se decidió derogar la legislación republicana con el siguiente argumento:

«Fárrago legislativo de la funesta República que anarquizó, indisciplinando, no sólo al personal de prisiones, sino también a la población reclusa de nuestros establecimientos penitenciarios ${ }^{5}$

En su lugar se restableció íntegramente el contenido del decreto de 14 de noviembre de $1930^{6}$, decreto que había significado un importante adelanto cuando se promulgó, pues su contenido recopilaba y ponía al día todo lo reglamentado hasta entonces en materia carcelaria. Sin embargo, su restitución seis años después supuso un serio retroceso ante los importantes avances obtenidos en legislación penitenciaria durante la Segunda República. Decisión de indudable importancia no sólo por el retroceso humanitario inherente a esa medida, sino también por su alcance temporal, pues esa reposición del marco jurídico

4. Rilova, I., "El centro penitenciario de Burgos durante la Guerra Civil. El año 1936», Revista de Estudios Penitenciarios, n. $^{\circ} 241$ (1989).

5. Así consta en la introducción del decreto por el que se derogó la legislación carcelaria de la República. Véase su contenido en Boletín Oficial del Estado, 24-XI-1936.

6. Se restableció este decreto el 22 de noviembre de 1936. Berduco, I. y otros, «El Ministerio (...)», p. 280. 
penitenciario aprobada en el último Gobierno de la Monarquía mantuvo su vigencia, aunque se fueron añadiendo distintas normas, hasta la aprobación del Reglamento de Prisiones en 1948.

\section{INSUFICIENTES CÁRCELES PARA ACOGER A TAN INGENTE NÚMERO DE PRISIONEROS}

Pero hasta que esas medidas se fueron poniendo en práctica al iniciarse el otoño de 1936, la confusión caracterizó la política penitenciaria en zona franquista, según se desprende de nuestro análisis sobre lo sucedido en Extremadura. Ocupada por los insurgentes la práctica totalidad de la provincia de Cáceres desde los primeros días de la insurrección de julio de 1936 y buena parte de la de Badajoz en el mes siguiente ${ }^{7}$, los primeros movimientos en materia carcelaria estuvieron marcados por el desconcierto, por lo demás comprensible ante un escenario de guerra civil.

En Cáceres, ante las reiteradas peticiones del Gobernados Militar para que se diera solución a la saturación de presos existente en la prisión provincial, en agosto de 1936 y desde la Auditoría de Guerra en Valladolid, que era de la que dependía en lo militar, se ordenaba que los reclusos condenados a penas de reclusión en consejos de guerra fueran trasladados a la prisión provincial de Salamanca. Sin embargo, los presos no fueron enviados a ese destino debido al rechazo mostrado por las autoridades insurgentes salmantinas y lo que es peor: se ignoraba dónde debían ser trasladados a cumplir condena. Otra instrucción posterior determinaba su envío a Sevilla, pero ante la negativa a aceptarlos por parte de los mandos hispalenses se optó por su permanencia en Cáceres.

Finalmente, ya en la segunda quincena de septiembre de 1936 y de nuevo desde la capital vallisoletana, en este caso desde la Jefatura de la VII División Militar, se cursaban las siguientes instrucciones a este respecto:

"Mientras no quede restablecida la normalidad nacional, todos los condenados deben continuar en el establecimiento penal donde se encuentren» ${ }^{8}$

Esa situación que se vivía en Cáceres, en la que los sublevados buscaban con empeño trasladar a otras provincias a los presos ya sentenciados, era consecuencia de la carencia de centros de reclusión para albergar al resto de presos, es decir, aquellos que aún no habían sido juzgados y que en esos meses eran los más numerosos. Los locales de la hasta entonces inhóspita e insalubre prisión provincial, sita en la popular calle Nidos de la capital cacereña ${ }^{9}$, pronto se atestaron de reclusos y se tuvieron que habilitar, pese a estar sus obras de construcción sin terminar, las instalaciones del nuevo centro penitenciario

7. Véase Chaves Palacios, Julián, Guerra Civil en Extremadura (1936-1939). Operaciones militares, Mérida, Editora Regional de Extremadura, 1997.

8. Archivo Histórico Provincial, Gobierno Civil de Cáceres, Sección de Orden Público, (en adelante AHPGC, OP), septiembre 1936.

9. Era conocida por sus deficientes instalaciones, con tres galerías y un patio sin apenas ventilación que la convertían en una auténtica mazmorra. 
provincial que se habían empezado a construir durante la República. Así lo ordenaba el recién nombrado Gobernador Civil Provincial, comandante de la Guardia Civil Fernando Vázquez, cuando tan sólo habían transcurrido cuatro días de su nombramiento:

"Visto el informe verbal del arquitecto municipal, Ángel Pérez, relativo a que los locales de la nueva cárcel que se está construyendo, denominados pabellón de mujeres, sociales y sótano de enfermería, reúnen las condiciones higiénicas y sanitarias para que provisionalmente puedan ser alojados los detenidos por orden gubernativa, he acordado incautarme los tres locales antes indicados y que se requiera al contratista de las obras de referencia para que cumpla cuanto dispone esta resolución $»^{10}$.

Esa utilización precipitada de las instalaciones del nuevo recinto penitenciario provincial no resolvió, sin embargo, el grave problema de la saturación de reclusos, como lo reconocía dos meses después el mismo Gobernador Civil, al indicar a su director, tras la detención del funcionario del catastro de Cáceres, Manuel Condón Borrella, que en caso de considerarle suficientemente castigado fuera puesto en libertad:

«Descongestionando de esa forma la cárcel que tiene un exceso de presos que pudiera ser perjudicial para la salud pública"

También se habilitaron barracones en el único edificio castrense con unidades militares en la capital cacereña, el cuartel del Regimiento Argel, donde se recluyeron prisioneros no sólo de procedencia castrense, sino también civil, aunque pronto resultaron insuficientes.

Contingencias que no cabe circunscribir en absoluto a los centros de reclusión de la capital de provincia, pues en las cárceles de los partidos judiciales y municipales se registraban similares dificultades. Escasamente dotadas, pronto se vieron desbordadas por la avalancha de prisioneros. Desde los pueblos se exponía a las autoridades los inconvenientes para dar cabida a tanta población reclusa, y casi todos manifestaban problemas similares: falta de espacio e insalubridad junto a carencia de recursos para la manutención de los presos.

Desconcierto y dificultades, pues, en las prisiones cacereñas para acoger a la numerosa población reclusa que eran similares en la otra provincia extremeña, Badajoz, donde la prisión provincial, sita en el palacio de Godoy, tras ser ocupada la capital pacense por las tropas insurgentes a las órdenes del coronel Yagüe el 14 de agosto de 1936, pronto se hizo pequeña y hubo que habilitar con ese mismo cometido sitios como el Picadero. Otros centros de reclusión importantes como los de Mérida y Almendralejo registraron similares problemas a la capital ${ }^{11}$.

10. Este oficio del Gobernador Civil estaba fechado el 23-VII-1936. AHPGC, OP, julio de 1936.

11. Véase GumérRez CASALA, José L., La represión en la provincia de Badajoz durante la Guerra Civil, Badajoz, Universitas, 2003. 
Además, la falta de higiene, las condiciones de vida infrahumanas y el hacinamiento fueron germen de epidemias entre los presos ${ }^{12}$, que originaron muertes y enfermedades difíciles de erradicar. En no pocos casos se tuvieron que arbitrar medidas excepcionales como la llevada a cabo en el segundo municipio cacereño en número de habitantes, Plasencia, donde los responsables del centro penitenciario municipal ubicado en el palacio del Marqués de Mirabel, ante el brote de sarna declarado en esa prisión en noviembre de 1936, decidieron el traslado de los presos afectado por esa enfermedad "al depósito situado en la calle Marqués de Constancia donde pueden estar aislados ${ }^{13}$.

En cuanto al mantenimiento, su abono a cada municipio se efectuaba desde la prisión provincial, que recibía los fondos del Servicio Nacional de Aprovisionamiento de Reclusos. Si bien ése era el canal establecido, cuestión distinta era la puntualidad en su recepción, que especialmente en los primeros meses de guerra va a registrar notables retrasos. Irregularidades que provocaron protestas como la efectuada por el responsable de la cárcel del partido judicial de Coria, que a finales de agosto de 1936 decía lo siguiente al Gobernador Civil de Cáceres:

"Hoy, día 23, no he podido socorrer a ninguno de los 119 presos que se encuentran en esta prisión por haber agotado la cuenta corriente del que suscribe, ascendiente a 4.000 pesetas, solicitando ayuda por creer de humanidad que los presos no se vean privados del socorro, único sostén para su alimentación’ 14.

Además, el problema de los abastecimientos a las cárceles se acentuó ante el impago a los suministradores de las facturas pendientes, con iniciativas como la del municipio cacereño de Hervás, donde su alcalde denunciaba este asunto en los siguientes términos:

«Pese a las manifestaciones de pronto pago de la cantidad adeudada a los distribuidores de esta cárcel de Partido -aproximadamente unas 12.000 pesetas-, dicho pago no llega y los comerciantes de esta localidad son de escasa disponibilidad, planteándose el grave problema de seguir suministrando más artículos y ser impotente esta alcaldía para obligar a hacerlo a los que se encuentran en situación tan comprometida. Además, los carniceros han negado ya el suministro por las referidas causas e incluso pretenden la elevación de los precios (...) $)^{15}$.

Sin embargo, el carácter fuertemente coercitivo del Nuevo Estado franquista impuso su ley y ese intento de desabastecer las prisiones por parte de los proveedores no llegó a fraguar. Y es que a la utilización de argumentos como "daño alguno puede afectarles por tratarse sólo de un anticipo que hacen al Tesoro de la Causa Nacional», se unieron amenazas de fuertes sanciones contra los que entorpecieran este servicio por considerarlo "desobediencia y negativa de

12. Véase sobre la situación de la población reclusa, LAFUENTE, Isaías, Esclavos por la patria. La explotación de los presos bajo el franquismo, Madrid, Temas de Hoy, 2002.

13. Archivo Municipal de Plasencia, Correspondencia, 1936.

14. AHPGC, O. Público, agosto 1936.

15. El oficio del alcalde de Hervás estaba fechado el 2-XI-1936. AHPGC, OP, noviembre 1936. 
auxilio a la autoridad constituida y de no hacerlo, sin perjuicio de ser detenido, le pararían las responsabilidades que hubiete lugar». Razones de fuerza, pues, les obligaban a cumplir con los suministros a las cárceles pese al retraso en el pago de lo facturado.

Junto a esa exigencia, para aliviar la carga económica que suponía esta labor de aprovisionamiento se barajaron soluciones como la propuesta por el alcalde de Plasencia de disminuir su coste a base de reducir los socorros, que pasarían de la asignación de 1,50 pesetas diarias por recluso, a 1 pesetas o 75 céntimos, según se considerase oportuno ${ }^{16}$. Se proponía, por tanto, reducir el coste preso/ día nada menos que a la mitad, lo que entrañaba abandonarlo deliberadamente a su suerte, que no era otra que dejarlo morir de hambre, o hacer recaer su alimentación sobre unos familiares, cuando los hubiere, que difícilmente podían soportar una carga diaria de esas características.

Afortunadamente en el Gobierno Civil de Cáceres se era consciente de las repercusiones que ese ajuste podía tener y se desestimó la petición al considerar que no era posible «modificar referidos socorros». Pero los abastecimientos eran una cuestión que derivaba de otra con mayor alcance y que requería una pronta solución. Nos estamos refiriendo al estudio de fórmulas que permitieran aliviar de detenidos las prisiones, y en las que cabe circunscribir iniciativas como la encabezada por el alcalde del municipio de Alcántara que, en octubre de 1936, efectuaba la siguiente solicitud a las autoridades provinciales de Cáceres:

"Con motivo de la fiesta de la Raza se pide el perdón a un recluso que tiene a su mujer enferma en casa y se ha adherido al Movimiento. También a otros presos. Muchos hijos, por esta causa, se encuentran sin padre ni pan. Lloran. La cárcel se encuentra en condiciones antihigiénicas, durmiendo los presos en el suelo. Es un pueblo sin desmanes, que vería con emoción la salida de todos, desbordándose el entusiasmo. Suplico no desoiga esta petición, a ruego mío y de todos. Dios premiará ${ }^{17}$.

Expresivo escrito tras los primeros meses de guerra civil, en el que de forma sucinta se ponían de manifiesto no sólo los problemas que aquejaban a las cárceles extremeñas en la zona controlada por los insurgentes, sino también el drama que debieron soportar muchas familias ante la falta de libertad de sus seres queridos. Posiblemente oficios como ése indujeron a las autoridades a apoyar iniciativas encaminadas a descargarlas cárceles de presos, al menos en esa línea cabe interpretar la orden cursada ese mismo mes de octubre a todos los municipios de la provincia de Cáceres, para que procedieran a «revisar las causas de detención de aquellos prisioneros menos significados en la etapa republicana por si procedía su liberación» ${ }^{18}$. Iniciativa, no obstante, de escasa

16. Esa medida se sometía a consulta al Gobernador Civil por parte del alcalde de Plasencia con fecha 2-IX-36: «Ante el gran número de presos existentes en el depósito municipal, y por alcanzar extraordinaria importancia la cuantía de los socorros que diariamente se les viene pagando por el Ayuntamiento". AHPGC, OP, septiembre 1936.

17. AHPGC, OP, octubre 1936.

18. El municipio de Perales del Puerto fue uno de los beneficiados por esa medida, al poner en libertad con fecha 11 de octubre de 1936, por estimar que estaban suficientemente castigados, a los 
repercusión, pues el número de detenidos siguió en aumento y hubo que buscar otras soluciones.

\section{CREACIÓN DE CAMPOS DE CONCENTRACIÓN PARA RECLUIR PRESOS DE GUERRA}

Éstas pasaban, necesariamente, por construir o habilitar nuevos edificios que serían destinados a centros penitenciarios. Edificios que era perentorio encontrar ante el fuerte incremento que, con el paso del tiempo, experimentó el número de prisioneros procedentes del frente de guerra. Para el control de éstos se crearon las Comisiones Clasificadoras de Prisioneros y Presentados, que en Extremadura tuvieron su sede principal en ambas capitales de provincia. Pero el problema principal no era su registro y procesamiento, sino el sitio donde recluirlos, de forma que se convirtió en una tarea apremiante la búsqueda de edificios adecuados para utilizarlos como centros penitenciarios.

Se van a crear con ese fin campos de concentración ${ }^{19}$, que constituirán la respuesta al ingente problema de la acumulación de presos en la retaguardia y en los frentes. Para regular su funcionamiento, a primeros de julio de 1937 se creó la Inspección de Campos de Concentración de Prisioneros, que dependía directamente de la Junta Técnica del Estado, siendo nombrado su máximo responsable el hasta entonces Gobernador Militar de Cáceres, coronel Luis de Martín Pinillos y Blanco de Bustamante ${ }^{20}$. Entre sus funciones se encontraba, además de coordinar el trabajo a desempeñar por los prisioneros, visitar los recintos y comprobar su estado.

Plazas de toros, cortijos de fincas rústicas, edificios fortificados, etc., se van a convertir en campos de concentración ${ }^{21}$. En Extremadura hubo una variada representación desde sus comienzos. En concreto, en la provincia cacereña tres núcleos de población contaron con estos centros de reclusión: Cáceres, Plasencia y Trujillo. En los tres se habilitaron las plazas de toros existentes con ese fin, aunque en la capital cacereña también se utilizó con ese cometido el cortijo de la finca "Los Arenales", ubicado a cuatro kilómetros de la capital en dirección a Portugal.

En cuanto a Badajoz, la prisión provincial de Santo Domingo se encontraba saturada de reclusos y se decidió descongestionarla con el traslado de presos a la finca Sagrajas, próxima a la capital pacense, donde se ubicó un campo de concentración. En Almendralejo, Mérida, Jerez de los Caballeros, Zafra, Puebla

reclusos «Arsenio Pereira Rivas, Lino Cordero Susaño, Antonio Martín Vidal y Benigno Morán Montero, de Perales del Puerto; y Eugenio Rodríguez Cano, Mariano Murguía Gómez, Floro Lázaro Calvo y José Moreno Fonseca, de Cadalso». AHPGC, OP, octubre 1936.

19. Véase RODRGo, Javier, Los campos de concentración franquistas, entre la historia y la memoria, Madrid, Siete Mares, 2003.

20. En el cargo de Gobernador Militar le sustituyó el coronel Sáez de Buruaga.

21. RodRIGO SÁnCHEZ, J., "Campos en tiempos de guerra. Historia del mundo concentracionario franquista (1936-1939)", en MOLInero, Carme y otros (eds.), Una inmensa prisión. Los campos de concentración y las prisiones durante la guerra civil y el franquismo, Barcelona, Crítica, 2003, pp. 19-36. 
de Alcocer y Herrera del Duque también existieron centros de reclusión, pero sin duda, el campo de concentración de referencia fue el de Castuera, que se creó para encarcelar a la ingente población reclusa procedente de la Bolsa de la Serena tras su ocupación por el ejército de Franco en el verano de 1938, y también para encerrar en él, al finalizar la guerra, a los republicanos detenidos tras la definitiva caída del frente.

La mayoría de los presos en Castuera eran extremeños y permanecían allí recluidos a la espera de ser juzgados en el preceptivo consejo de guerra. Diversos barracones y un muro construido con alambradas de espino guarnecido por soldados bien pertrechados constituían la fisonomía de este siniestro campo, que albergó a miles de reclusos que padecieron carencias de todo tipo en unas condiciones insalubres, y donde la existencia de piojos y sarna constituía la nor$\mathrm{ma}^{22}$. Una estancia, por tanto, precaria, sobre la que contamos con testimonios como el facilitado por Rafael Caraballo Cumplido, soldado republicano que fue recluido en este campo tras combatir en los frentes de Aragón, Andalucía y Extremadura:

"Al terminar la guerra fui detenido y me trasladaron, a mediados de mayo, al campo de concentración de Castuera donde me reuní con mi hermano Alfonso, al que habían recluido allí tras ser detenido cuando marchaba para Alicante. Al llegar al campo, como los barracones estaban ocupados, nos tuvieron que meter en unas chabolas construidas con unos perfiles metálicos y alambres de espino de las trincheras. Después fuimos destinados al barracón 23. Los barracones lo mismo que se llenaban se vaciaban. Venían los falangistas y se los llevaban a sus pueblos. Unos llegaban a su destino y otros desaparecían en el camino. La mayoría eran fusilados. Había uno que era hermano de un compañero nuestro que estaba en las oficinas del campo y rompía todos los avales que mandaban los familiares desde los pueblos, pues sabía que nada más llegar a su localidad los mataban. Sobre la situación tan difícil en que nos encontrábamos en los barracones decir que a mi hermano Alfonso le entraron ganas de defecar cuando estábamos durmiendo. Como no podía aguantarse salió corriendo por la ventana, pero nada más verlo el guardia le disparó dos tiros y al segundo apareció Alfonso dentro del barracón, que ya no tenía ganas de evacuar ${ }^{23}$.

Como se desprende del testimonio de Rafael, la situación de los reclusos en el campo de concentración franquista más importante de Extremadura era deplorable. Investigaciones que se están desarrollando desde la Universidad extremeña sobre este centro de reclusión nos permitirán profundizar no sólo en aspectos como la identidad y número de reclusos que pasaron por él, sino también en las vicisitudes y vejaciones que afectaron a éstos.

Trujillo fue otra de las poblaciones extremeñas con campo de concentración. Sobre su creación, en el verano de 1937, las instrucciones cursadas por los mandos militares a su alcalde eran taxativas: "con el fin de practicar en la plaza de toros los trabajos para obras de saneamiento e higiene y seguridad, ya que ha

22. Gallardo, Jacinta, La Guerra Civil en La Serena, Badajoz, Diputación Provincial, 1994, p. 201.

23. Este párrafo corresponde a las memorias que Rafael ha dejado escritas y que amablemente nos ha facilitado para su consulta. 
de ser habilitada urgentemente para prisión de evadidos y prisioneros de guerra, se ponen a disposición de ese Ayuntamiento un total de 3.582 pesetas para hacer frente a los gastos de habilitación ${ }^{24}$. Por tanto, se transfería una cantidad de dinero a las mermadas arcas municipales trujillanas para poner a punto este improvisado centro penitenciario, especialmente en acciones como reforzar muros y puertas que le dieran una mayor seguridad.

\section{Campo de concentración de prisioneros de Trujillo Justificante de revista del comisario Septiembre de 1937}

\begin{tabular}{|l|l|l|l|}
\hline \multicolumn{1}{|c|}{ Responsables } & \multicolumn{1}{|c|}{ Nombres } & \multicolumn{1}{c|}{ Destino } & Honorarios mensuales \\
\hline $\begin{array}{l}\text { Teniente coronel de } \\
\text { la Guardia Civil en la } \\
\text { reserva }\end{array}$ & $\begin{array}{l}\text { Ángel } \\
\text { Hernández } \\
\text { Martín }\end{array}$ & $\begin{array}{l}\text { Jefe y máximo } \\
\text { responsable del } \\
\text { campo }\end{array}$ & Gratificación de 125 pts. \\
\hline $\begin{array}{l}\text { Teniente de la Guardia } \\
\text { Civil retirado }\end{array}$ & $\begin{array}{l}\text { José Benito } \\
\text { Sancho }\end{array}$ & Auxiliar & Gratificación de 50 pts \\
\hline $\begin{array}{l}\text { Teniente de Carabineros } \\
\text { retirado }\end{array}$ & $\begin{array}{l}\text { Victoriano } \\
\text { Sánchez García }\end{array}$ & Auxiliar & Gratificación de 50 pts \\
\hline $\begin{array}{l}\text { Teniente de Caballería } \\
\text { retirado }\end{array}$ & $\begin{array}{l}\text { Bartolomé } \\
\text { Ramos Lorenzo }\end{array}$ & Auxiliar & Gratificación de 50 pts \\
\hline
\end{tabular}

Del mismo modo correspondía al Gobernador Militar Provincial nombrar a sus responsables, cargos que recayeron, por lo general, en militares o guardias civiles que se encontraban en la reserva. Era una forma de tenerlos activos, con el aliciente de compensar sus servicios con una gratificación, como se puede apreciar en el cuadro que se acompaña sobre Trujillo. Su labor consistía en velar por el mantenimiento del recinto y controlar a los presos, trabajo en el que debían poner el mayor celo pues eran objeto de inspección de forma regular. Citamos como ejemplo la visita cursada en 1938 por los servicios de Inspección de Campos de Concentración de Prisioneros a la plaza de toros de Trujillo, en la que detectaron las siguientes carencias sanitarias:

«Se servirá disponer lo necesario para que sea habilitada otra zanja o letrina, más la existente, por considerar ésta insuficiente. Así dispondrá lo conveniente para que se instale una enfermería al lado de la utilizada actualmente como despacho del Oficial Médico, y si por ser dicha habitación de paso y se viera en la práctica que no reunía condiciones para servir de enfermería, habilitará otra habitación de ese Campo a los fines indicados» ${ }^{25}$.

24. Esta instrucción tenía fecha del 14-VII-1937. Archivo Municipal de Trujillo, Correspondencia, 1937.

25. El responsable del campo de concentración hizo seguir este informe al alcalde de Trujillo el 9XI-1938, y le indicaba que "a fin de que no sean tan gravosas estas obras a su Ayuntamiento, la mano de obra puede ser sustituida por prisioneros que en la actualidad tiene este campo». Archivo Municipal de Trujillo, Correspondencia, 1938. 
Recomendaciones, como se puede comprobar, precisas, que muestran el estado tan deficiente de las instalaciones de un recinto penitenciario atestado por una población reclusa que trataba de sobrevivir en lugar tan infesto. Estado de ese centro que cabe extender por igual al resto de prisiones extremeñas $y$, por lo general, a la mayor parte de las cárceles ubicadas en zona franquista ${ }^{26}$.

\section{MOVILIDAD EN LA POBLACIÓN RECLUSA: TRASLADO A OTRAS PRISIONES}

Pese a la creación de esos establecimientos penitenciarios, lo cierto es que la población reclusa aumentaba a medida que avanzaba la guerra, lo que hizo necesario habilitar nuevas prisiones. En esa línea cabe enjuiciar la siguiente circular del Gobernador Civil de Cáceres a todos los Ayuntamientos de la provincia en octubre de 1937:

"Los señores alcaldes remitirán a este Gobierno, en el plazo de 48 horas, relación de todos los locales que puedan ser requisados con objeto de utilizarlos como cárcel, con el fin de que puedan extinguir condena los militares sancionados. Se procurará que dichos locales reúnan las condiciones de higiene, luz, agua y fácil custodia ${ }^{27}$.

Las contestaciones fueron de lo más variadas. Desde pueblos como Cuacos de Yuste se ofrecían tres locales situados en el mismo monasterio de Yuste. Por su parte, en la localidad de Granadilla se daba cuenta de la existencia de un castillo, en estado ruinoso, que hacía unos 50 años había servido de cárcel del Partido. Desde Navalmoral de la Mata se proponian las escuelas de párvulos. En otros municipios se ofrecían domicilios de particulares, con ejemplos como la propuesta del Ayuntamiento de Ibahernando que ponía a disposición una casa propiedad del vecino Abelardo Montero Curiel «que con toda su familia se había marchado del municipio en julio de 1936 y que por su solidez y fácil vigilancia podía ser requisada y habilitada para cárcel». En Plasencia, en cambio, nada podía hacerse en ese sentido, pues como informaba su alcalde:

"Están establecidos en esta población seis hospitales de guerra y en vías de creación otros dos más; funcionan dos cárceles y pronto va a abrirse otra con destino a presos gubernativos. Además se encuentran requisados todos los locales que reúnen condiciones para los fines que se interesan ${ }^{28}$.

El principal centro penitenciario de Cáceres era la prisión provincial, donde se ingresaba a los prisioneros que tuviesen abierto expediente procesal y también al ya sentenciado por los tribunales castrenses. Además, dadas sus garantías en materia de seguridad en comparación a otras prisiones, se trasladaba a

26. Sobre la situación del recluso en las cárceles durante el régimen de Franco, véase SerRano, R. y Serrano, D., Toda España era un cárcel. Memoria de los presos del franquismo, Madrid, Aguilar, 2002. Y sobre sus vicisitudes en prisiones provinciales durante la Guerra Civil, véase VECA SOMBriA, S., Control sociopolítico e imposición ideológica: la provincia de Segovia, 1936-1939. Un episodio en la implantación del franquismo, Madrid, tesis doctoral, inédita, 2003.

27. Boletín Oficial de la Provincia de Cáceres, 27-X-1937.

28. AHPGC, OP, octubre 1937. 
ese centro, siempre según criterio de la Comisión Clasificadora de Prisioneros y Presentados, a determinados reclusos ingresados inicialmente en campos de concentración, que al ser considerados peligrosos por su responsabilidad en supuestos hechos delictivos interesaba tenerlos en esa cárcel.

Ese movimiento de presos hacia cárceles de mayor seguridad que los improvisados campos de concentración fueron frecuentes, del mismo modo que la salida masiva de reclusos de la prisión provincial tras hacerse firme la sentencia a pena de reclusión en consejo de guerra. Éstos eran trasladados a otras prisiones de la zona franquista a cumplir sus condenas, y realizaban el viaje por ferrocarril con una estricta custodia a cargo de la Guardia Civil ${ }^{29}$. Y prueba de que el control sobre la vida penitenciaria del preso continuaba en el lugar de destino era la documentación que se acompañaba al traslado: una hoja de conducta, copia de la sentencia y liquidación de la condena impuesta. Se hacía constar, además, si dejaba alguna responsabilidad pendiente.

\section{Traslado a otros centros penitenciarios de reclusos ingresados en la prisión provincial de Cáceres entre los años 1937-1943}

\begin{tabular}{|l|c|c|c|c|c|c|c|c|c|}
\hline $\begin{array}{l}\text { Prisiones } \\
\text { de destino }\end{array}$ & $\mathbf{1 9 3 7}$ & $\mathbf{1 9 3 8}$ & $\mathbf{1 9 3 9}$ & $\mathbf{1 9 4 0}$ & $\mathbf{1 9 4 1}$ & $\mathbf{1 9 4 2}$ & $\mathbf{1 9 4 3}$ & $\begin{array}{c}\text { Sin } \\
\text { fechar }\end{array}$ & Total \\
\hline Aranjuez & & & & 16 & & & & & 16 \\
\hline Astorga & 5 & 1 & 174 & 1 & & & & 2 & 183 \\
\hline Burgos & & 137 & & & 26 & & & & 163 \\
\hline Celanova & & 1 & & & 47 & & & & 48 \\
\hline Cuéllar & & 11 & 1 & & & & & & 12 \\
\hline $\begin{array}{l}\text { Dos } \\
\text { Hermanas }\end{array}$ & & & & 12 & 4 & & & & 16 \\
\hline Dueso & & & & & 6 & & & & 6 \\
\hline $\begin{array}{l}\text { Isla San } \\
\text { Simón }\end{array}$ & & & 13 & 2 & 2 & & & & 17 \\
\hline Madrid & & & 7 & 5 & 5 & 1 & 1 & 1 & 20 \\
\hline Pamplona & 1 & & 61 & & & & & 1 & 63 \\
\hline $\begin{array}{l}\text { Pto. Sta. } \\
\text { María }\end{array}$ & 40 & 36 & & & 10 & & & 2 & 88 \\
\hline Santander & & 16 & & & & & & & 16 \\
\hline Saturrarán & & 9 & & 2 & 20 & & & & 31 \\
\hline $\begin{array}{l}\text { Talavera } \\
\text { Reina }\end{array}$ & & 3 & 1 & 3 & 4 & 2 & 19 & 1 & 33 \\
\hline
\end{tabular}

29. Como ejemplo, se transcribe el siguiente parte del cabo de la Guardia Civil, Eladio García Robledo, al recibir para su traslado a varios presos: "A las 9 horas de hoy me hago cargo de 24 detenidos para conducirlos a los puntos que se indican conforme a lo ordenado por la superioridad. Me hago cargo además de 211,20 pesetas correspondientes a los mismos. Cáceres, 31-1-1939, III año triunfal». APPCC, Exp. 4.979, Antonio Rubio García. 


\begin{tabular}{|l|c|c|c|c|c|c|c|c|c|}
\hline Tarragona & & & 1 & 50 & & & & & 51 \\
\hline Zaragoza & & & & 3 & 38 & 1 & 1 & & 43 \\
\hline Otras & 2 & 2 & 12 & 11 & & & 2 & & 29 \\
\hline TOTAL & 48 & 216 & 270 & 105 & 162 & 4 & 23 & 7 & 835 \\
\hline
\end{tabular}

FUENTE: Archivo de la prisión provincial de Cáceres

En el cuadro que exponemos sobre los traslados a otros centros penitenciarios de ámbito nacional desde la prisión provincial de Cáceres se contabilizan entre 1937, año en que se iniciaron, y 1943, un total de 835 reclusos. La mayoría de ellos se produjeron entre 1938 y1941, con años como 1939 en que partieron 270 presos, de los que 174 se enviaron a la prisión de Astorga y 61 a la de Pamplona, concretamente al funesto Fuerte de San Cristóbal ${ }^{30}$. También los 216 de 1938, de los que 137 se destinaron a la cárcel de Burgos y 36 al penal del Puerto de Santa María. Las mujeres también fueron objeto de traslado durante esos años, con prisiones como las de Tarragona y Saturrarán que fueron receptoras de 51 y 31 reclusas, respectivamente ${ }^{31}$.

\section{FINALIZACIÓN DE LA GUERRA: MASIVAS DETENCIONES DE REPUBLICANOS}

En 1939, con la finalización de la contienda, la llegada masiva de personas procedentes del bando republicano propició nuevas detenciones en la mayoría de los pueblos extremeños. Y para desarrollar con la mayor diligencia posible esa labor se requirió la implicación de las corporaciones municipales, a las que se hicieron seguir los siguientes criterios en la clasificación de esa población:

"1.- Individuos acusados de delitos concretos contra personas y bienes, tales como asesinatos, detenciones, saqueos, quema de imágenes; o que hubieran ostentado cargos políticos o sindicales, tales como alcaldes, concejales, secretarios, directivos de Casas del Pueblo, etc. seguirán en Prisión a disposición del Ilmo. Sr. Auditor.

2.- Individuos que pertenecieron a partidos del Frente Popular o Casas del Pueblo sin cargos ni destaque seguirán en libertad pero con cierta vigilancia de la Autoridad de quien dependan, no pudiendo cambiar de residencia sin permiso. Los comandantes de puesto de la Guardia Civil llevarán ficheros con sus antecedentes, para en cualquier momento saber todos los individuos que en esas condiciones se hallan en terreno de su jurisdicción.

30. En ese Fuerte tuvo lugar una fuga masiva de reclusos el 22 de mayo de 1938 y en la búsqueda de los fugados fueron pasados por las armas dos centenares de presos, entre ellos los siguientes cacereños trasladados a ese centro desde la prisión provincial de Cáceres: Albino y Escolástico Carretero Hernández, Segundo Fernández Frades, los tres de San Martín de Trevejo; Juan Harto Gómez y Diego Mogollón Acedo, de Malpartida de Cáceres. A. K. T., Navarra 1936. De la esperanza al terror, Pamplona, ed. el autor, 1986, v. I, p. 96 y ss. y v. II, p. 353 y ss.

31. Véase sobre mujeres encarceladas, VINYES, R., Irredentas. Las presas politicas y sus hijos en las cárceles franquistas, Madrid, Temas de Hoy, 2002. Cuevas, T., Cárcel de mujeres (1939-1945), Barcelona, Siroco, 1986. 
3.- Individuos de buenos antecedentes y adictos al Movimiento quedarán en completa libertad y podrán hacer vida normal». ${ }^{32}$.

Esas indicaciones, sin embargo, apenas se respetaron. Las detenciones se acrecentaron de nuevo y las cárceles se volvieron a llenar de reclusos con los consiguientes problemas de carencia de locales adecuados, masificación e insalubridad, falta de recursos para socorrerlos, etc. La solución provisional a ese nuevo escenario penitenciario fue que estos presos, tras la clasificación pertinente, ingresaran en los campos de concentración más próximos a los lugares de detención, donde pasaban a depender directamente del Gobernador Militar Provincial, tras la supresión de las Comisiones Clasificadoras de Prisioneros y Presentados por Orden de 12 de abril de 1939.

Transcurridos los primeros meses desde la finalización de la guerra, la congestión de reclusos inicial se fue atenuando y, de forma gradual, en provincias como la de Cáceres la escasez de centros de reclusión dejaba de constituir un problema. En concreto, en la prisión provincial, con el progresivo traslado de presos a otras cárceles para cumplir condena y la ralentización que registraron los ingresos, se descongestionaron algunas de sus dependencias, lo que permitió la recepción de reclusos procedentes, en su mayor parte, de prisiones ubicadas en la provincia. La cárcel militar existente en el cuartel del Regimiento Argel, ubicado en la capital cacereña, fue una de las primeras beneficiadas. Allí se encontraban recluidos cerca de un centenar de prisioneros que saturaban el recinto. Para aliviar esa concentración de presos, desde finales de 1939 se habilitaron en la prisión provincial celdas especiales a las que fueron trasladados los 50 prisioneros pertenecientes al personal de tropa, con la condición de «permanecer solos y sin mezclarse con los restantes reclusos civiles» ${ }^{33}$.

En otro orden cabe señalar que la población reclusa concentracionaria dejó de estar a disposición de la Inspección de Campos y pasó a estar controlada directamente por la jurisdicción militar. Medida que originó su paulatino traslado a las prisiones provinciales para serles incoado el correspondiente consejo de guerra. Se iniciaba de esa forma la progresiva desaparición de los funestos campos de concentración, que como ha señalado J. Rodrigo: "cada vez más dejaban de ser campos en tiempos de guerra civil, para ser campos en tiempos de guerra mundial» ${ }^{34}$.

En contrapartida, mediante la Ley de 8 de septiembre de 1939 se creó el Servicio de Colonias Penitenciarias Militarizadas, que tenía como principal cometido, según se indica en su texto introductorio:

32. Estos criterios eran remitidos mediante Circular del Gobernador Militar de Cáceres, de fecha 19-VII-1939, a los Ayuntamientos de la provincia. Archivo Municipal de Serradilla, Correspondencia, 1939.

33. APPCC, Exp. 1449-38, José Pousas Grande.

34. Rodrico, J., "Campos en tiempos (...)", p. 34 
«La organización y utilización de los penados en la ejecución de obras públicas o particulares, y en la explotación, con carácter provisional o permanente, de determinadas industrias cuando éstas tengan el carácter de nuevas 0 , no siéndolo, sean necesarias o convenientes para la Economía Nacional ${ }^{35}$.

El Servicio de Colonias Penitenciarias Militarizadas dependía de la Presidencia del Gobierno, tenía una organización militar y estaba vinculado al Ministerio de Justicia a través del Patronato de Redención de Penas por el Trabajo ${ }^{36}$. Éste proporcionaba a los penados, como veremos más adelante, la posibilidad de aligerar sus condenas mediante el desarrollo de trabajos que, por lo general, guardaban relación con las obras públicas previstas por el régimen.

Se organizó en Agrupaciones, de forma que en enero de 1940 comenzó a funcionar la $1^{a}$ Agrupación, que se instaló en Sevilla, y en años sucesivos se fueron creando otras ${ }^{37}$. En Extremadura se creó la $2^{a}$ Agrupación de Colonias Penitenciarias Militarizadas, que tuvo su ubicación en Montijo, donde llevó a cabo la construcción del Canal que lleva el nombre de esa población ${ }^{38}$. Por tanto, en el transcurso de la década de los cuarenta la situación carcelaria en Extremadura se fue estabilizando. Como era de prever, descendió notablemente el número de detenciones, pese a que en esos años, como consecuencia del desarrollo experimentado por la actividad guerrillera contra el régimen, también se registró una importante nómina de presos, aunque no en los niveles de la contienda armada de 1936-193939.

\section{VICISITUDES DE LA POBLACIÓN RECLUSA REPUBLICANA}

Lógicamente, quien sufrió directamente los problemas del mal estado de los centros carcelarios fue la población reclusa. A la falta de higiene característica en este tipo de centros se unió, especialmente en los primeros meses de Guerra Civil, el estado de abandono a que estaban sometidos y los malos tratos recibidos, que convertían las cárceles en un auténtico martirio para los presos ${ }^{40}$. E1 suplicio comenzaba en las prisiones locales. Sobre su estancia en las mismas hemos recabado algunos testimonios de personas que vivieron personalmente la experiencia, entre los que destacamos el del socialista Arturo Domínguez, vecino del municipio cacereño de Navas del Madroño, que resultó detenido, junto a sus paisanos Juan Caballero Pino y Ángel Barrado Tejeda, el 22 de julio de 1936 tras el control de su pueblo por los sublevados:

35. Boletín Oficial del Estado, 17-IX-1939.

36. El Patronato se creó mediante Orden de 7 de octubre de 1938.

37. Véase Gutrérrez Molina, J. L., "Los presos del Canal. El Servicio de Colonias Penitenciarias Militarizadas y el Canal del Bajo Guadalquivir (1940-1967)", en Molinero, C., SAla, M. y Sobrequés, J. (eds.), Una inmensa prisión..., pp. 61-79.

38. Guttérrez Casala, José L., Las Colonias Penitenciarias de Montijo, Mérida, Editora Regional, 2002.

39. Chaves Palacios, Julián, Huidos y maquis. La actividad guerrillera en la provincia de Cáceres, $19.36-$ 1950, Cáceres, Diputación Provincial de Cáceres, 1994, p. 137 y ss.

40. Véase Torres, R., Los esclavos de Franco, Madrid, Obreron, 2000. 
«Los tres fuimos trasladados a la prisión municipal de Arroyo de la Luz. Allí nos juntamos con Medardo Cervera, alcalde durante el Frente Popular en Arroyo. Parece mentira como lo maltrataban cuando él fue quien evitó que los republicanos de Arroyo, con armas en la mano, saliesen a la calle tras el 18 de julio y linchasen a los componentes de la Benemérita de ese pueblo. También conocí en prisión a un tal Pío, al que mataron en el mismo Ayuntamiento por rebelarse a los que le estaban pegando "prefiero que me deis un tiro -decía- a que me peguéis". A los pocos días de nuestra detención desaparecieron unas escopetas de Arroyo, como consecuencia de ello nos sacaban a los tres de Navas casi todas las noches de la cárcel y nos propinaban grandes palizas, mientras nos preguntaban por el paradero de dichas armas pese a decir hasta la saciedad que nada sabíamos.

El oficial de la Guardia Civil, Planchuelo, y un tal Rosario, a menudo en estado de embriaguez, fueron los principales autores de esas palizas. En ocasiones, cuando las llevaban a cabo decían ¡Dejadlos, si los vamos a fusilar! Al cabo de los meses, sin juicio ni nada que se pareciese, nos llegó la sentencia: seis meses de arresto y 50.000 pesetas de multa. A mí me embargaron la casa para afrontar parte de esa sanción. Después nos liberaron ${ }^{41}$.

Arturo, por tanto, además del tiempo de reclusión y las torturas y vejaciones que debió soportar, fue castigado con una multa a la que hizo frente con el embargo de su vivienda, que era el único bien que disponía. Incautación que sólo supuso una parte de la cuantiosa multa impuesta y que seguramente fue empleada, al menos una parte, para sufragar los gastos originados por su permanencia en prisión, que ascendían a 1,50 peseta diaria ${ }^{42}$. No obstante, a pesar de todas las adversidades que pasó en la cárcel, su final no estuvo marcado por la tragedia: había conseguido, pese a las amenazas de los guardianes, salvar su vida. Otros, como el maestro de enseñanza y compañero de prisión Ángel Barrado, no tuvieron esa fortuna, ya que meses después, tras ser condenado a pena de muerte en consejo de guerra, fue fusilado en la capital cacereña ${ }^{43}$.

En los depósitos municipales la característica principal hasta que se producía el traslado del detenido a otros centros eran los malos tratos. Sin embargo, en las prisiones provinciales la práctica de torturas a los presos no estaba tan extendida. Eso al menos se desprende de los testimonios que hemos recogido al respecto, entre los que destacamos el ofrecido por José Carrasco Canales, que contaba con 20 años en 1936, y visitaba frecuentemente la prisión provincial de Cáceres (cárcel "Vieja») pues tenía allí recluidos, desde agosto de 1936, a sus hermanos Octavio y Benjamín; y a su tío, ex alcalde de Cáceres, Antonio Canales.

41. Arturo Domínguez, ya fallecido, era secretario de las Juventudes Socialistas de Navas del Madroño en 1936 y nos ofreció este testimonio en 1988.

42. El Ayuntamiento de Arroyo de la Luz aportaba desde el 8 de agosto de 1936 un total de 1,50 pesetas diarias por el mantenimiento de cada uno de los tres reclusos, y exigió a la Corporación de Navas del Madroño, a comienzos de diciembre, que le abonara "las 526,50 pesetas a que ascendían los gastos por la estancia en el depósito municipal de los tres vecinos de ese municipio". AHPGC, OP, diciembre 1936.

43. Lo pasaron por las armas el 25 de diciembre de 1937 tras haber sido condenado a última pena en consejo de guerra. APPCC, Exp. 341-37, Ángel Barrado Tejeda. 
"Visitábamos todos los días, a primeras horas de la tarde, la cárcel, y les llevábamos ropa y alimentos que entregábamos en un vestíbulo. La comunicación con ellos, a través de una rejilla, sólo nos la permitían una o dos veces por semana, aunque no recuerdo bien este último extremo. Por otro lado aprovechaba que los sacaban por la mañana en camiones para realizar trabajos forzados, al parecer en la carretera de Monroy, para pasarle a mis hermanos, a su paso por la calle San Blas, trozos de papel escritos, bien doblados, que lanzaba al camión y, a viceversa, ellos también me los tiraban a mí. En los mismos, mi hermano me indicaba las cosas que necesitaban: ropa, libros, etc. Esa labor la realicé hasta primeros de diciembre que me descubrieron. Para entonces Octavio ya había dejado de salir de prisión por estar sentenciado a pena de muerte. Cuando comprobaron que las notas que les pasaba carecían de importancia, y que los informes que habían solicitado sobre mi conducta eran Favorables, sólo me detuvieron dos días. Eso sí, me pusieron en libertad bajo la condición inexcusable de marcharme a mi pueblo: Arroyo de la Luz» ${ }^{44}$.

Como se indica en el testimonio anterior, por las mañanas se sacaba en camiones a la población reclusa y se les llevaba hasta el extrarradio de la capital donde realizaban trabajos en caminos y cercados. Bien entendido que los únicos que salían a realizar esa labor eran aquellos presos sobre los que aún no se había dictado sentencia o que no estuviesen recluidos en régimen de incomunicación. Y en cuanto a las visitas de familiares, si bien se les permitía que les llevaran alimentos y vestimenta, sin embargo la comunicación personal no era diaria. Desde el Gobierno Militar de Cáceres se estableció, en los reclusos que tuviesen autorización para ello, el siguiente régimen de visitas: "los lunes para los residentes de fuera de la capital y los jueves para los de la plaza» ${ }^{45}$.

\section{ESTADO PERMANENTE DE INQUIETUD Y PESIMISMO DE LOS PRESOS}

En centros como la prisión provincial cacereña existían distintas dependencias para mujeres y hombres, que desarrollaban su vida carcelaria bajo el signo de la inquietud e impaciencia a la espera de ser juzgados o pendientes del cumplimiento de sentencia, especialmente en los casos de condena a pena de muerte. Además, la obligación diaria de participar en el toque de oración, de formar, desfilar y cantar los himnos del Movimiento originaba estados de tensión permanente. Situación que explica, pese a la rígida vigilancia existente, que al menor resquicio los reclusos trataran de darse a la fuga ${ }^{46}$.

La situación de los presos se veía agravada por la falta de higiene y escasa alimentación lo que provocó defunciones de reclusos, aunque es necesario indicar

44. José Carrasco nos facilitó este testimonio en su residencia de Arroyo de la Luz en 1988.

45. Diario Extremadura, 14-VIII-1937.

46. En el traslado a la cárcel de Trujillo con el fin de descongestionar de presos la de Cáceres, el 27 de octubre de 1936, de los reclusos Jesús Navarro Degano, Alfonso Suero Pizarro, Francisco Ramos Nieto, Tomás Bernal Sánchez, Justo Calderón Puerto, Antonio Solís Tapia, José Ramos Crijota, Juan Antonio Escobar Guisado, Agustín Sánchez Galán, Juan Cabanillas Casado y Manuel Gutiérrez Rodríguez, la camioneta que los trasladaba volcó en la carretera y éstos aprovecharon "para darse la fuga a pesar de los esfuerzos por capturarlos por parte de los falangistas que los custodiaban». AHPGC, OP, octubre 1936. 
que éstas son difíciles de cuantificar ya que en las inscripciones realizadas en el Libro de Defunciones del Registro Civil no se hizo constar, salvo excepciones ${ }^{47}$, la procedencia del óbito. No obstante, efectuado el correspondiente análisis de las muertes producidas en la prisión provincial de Cáceres entre los años 1936 y 1942, hemos contabilizado un total de 136 presos fallecidos en ese centro ${ }^{48}$. De ellos, más de la mitad se produjeron en un año especialmente duro para la España de posguerra: 1941; seguido de otro no menos complicado: 1940, que acaparó una cuarta parte de esas muertes. Sin embargo, durante el período de guerra civil sólo se registraron 19 casos que se repartían entre 1937-1939, con 7 , 8 y 4 fallecidos, respectivamente. Como causas de muerte figuran: enterocolitis, caquexia por desnutrición, bronquitis, tuberculosis, miocarditis, etc., es decir, enfermedades asociadas a la debilidad física y psíquica que sufría el recluso.

Junto a esas contingencias de la población reclusa nos encontramos con los informes que sobre su conducta elaboraban los responsables de la cárcel, que tenían como destino las autoridades civiles y militares provinciales. En ellos se vertían datos sobre los presos que mantenían buena conducta y habían dado muestras de arrepentimiento, con ese fin se llevaban en cuenta aspectos relacionados con el cumplimiento de signos externos como dar los correspondientes vivas al Caudillo, al Glorioso Ejército y a la España Católica, con las formalidades al uso: brazo extendido y mano abierta. A quienes se estimaba que cumplían esos preceptos, y en esa valoración cabe introducir factores de aleatoriedad fácilmente deducibles, se les llevaba en cuenta no sólo a efectos de conmutaciones de penas, que se hacía constar en su expediente procesal, sino para el desempeño de labores de colaboración con el funcionariado de la prisión.

Esas colaboraciones consistían, en no pocos casos, en actuar como confidentes, es decir, facilitaban información a la dirección de la prisión sobre el comportamiento de los demás reclusos. Práctica, por lo demás, bastante extendida entre los presos, aunque no todos se prestaban a esa complicidad. Fue el caso del recluso Cecilio Román, vecino del municipio cacereño de Perales del Puerto, que fue detenido en agosto de 1936 tras desempeñar en su pueblo las funciones de concejal socialista durante los meses de gobierno del Frente Popular, y nos ha facilitado el siguiente testimonio:

"Tras ser detenido, el brigada de la Guardia Civil, Planchuelo, me llevó a la prisión de Cáceres -cárcel Vieja-como "chivato". Me negué a entrar en ese tipo de

47. Una de ellas la hemos encontrado en el Registro Civil de Trujillo, que tiene inscritos en el Libro de Defunciones del año 1940 un total de 28 fallecimientos, en los que se cita no sólo la causa de muerte (en la mayoría de ellos: fallos cardíacos, anemia, enterocolitis, heridas infectadas y bronconeumonías), sino también el lugar de defunción: la prisión o el campo de concentración, según los casos.

48. En la prisión provincial de Badajoz la cifra de fallecidos fue más elevada al alcanzar los 346 fallecidos. Guttérrez Casala, José L., Las Colonias Penitenciarias..., p. 78. 
maniobras. Pese a mi negativa, me hacían declarar cada cinco o seis días por si había escuchado alguna cosa, no informándoles de nada ${ }^{49}$.

En cuanto a los campos de concentración, la supervivencia constituía el principal objetivo de los prisioneros de guerra. Ubicados en lugares seleccionados más por razones de amplitud que por cualquier otro criterio de habitabilidad, concentraron en los años de mayor reclusión a un ingente número de presos que vivían hacinados y desnutridos lo que provocó bastantes muertes por inanición. Sobre su experiencia como recluso en el ya citado campo de concentración de Los Arenales, Arturo Domínguez nos indicó en su testimonio:

«Había muchísima gente allí encerrada y todos nos encontrábamos hacinados. Nos daban de desayunar agua, ellos decían que era caldo, y para comer siempre latas de sardinas en aceite con pan. No pocos, sobre todo los que eran de fuera y sus familiares no estaban en Cáceres para poder facilitarles alimentos, fallecieron a causa del hambre.

En una ocasión trajeron de Lérida a unas 200 mujeres que habían sido trasladadas en tren, al parecer precintado. Cuando llegaron a Cáceres no sabían dónde se encontraban. A todas las encerraron en dos o tres tinados de Los Arenales separadas de los hombres. Hacían sus necesidades a través de un agujero en la pared que comunicaba al exterior".

Existencia, pues, tremendamente difícil y complicada, que rayaba la mera lucha por la subsistencia, que sin embargo la propaganda franquista trataba de contrarrestar ante la opinión pública con iniciativas como la publicación en la prensa provincial, a finales de 1937, de una supuesta carta que uno de los reclusos de Los Arenales remitía como contestación a la de un familiar, con el siguiente texto:

«(...) También me dices que tu hermano Clemente falleció defendiendo la causa nacional en el Frente de Oviedo, lo mismo haríamos nosotros hoy porque ya vimos cómo nos trataron los rojos y como lo hacen los nacionales. Va un abismo. Así que ten paciencia que Franco no tiene en olvido a las familias de los caídos en campaña $y$, según tengo entendido, también socorre a nuestras familias, así es que esto se tiene siempre en la memoria de los que hacen el bien, porque yo no tenía quién me ganara un céntimo para dar de comer a los hijos y están bien atendidos que es mi orgullo. Lo que no hicieron los rojos: dar de comer al hambriento. Así es que no sé con qué pagaré esto que hacen por mí y la familia. Por tanto, que termine la guerra con el triunfo del Generalísimo Franco, porque es a quien tenemos que agradecer la vida, ${ }^{50}$.

Misiva, como se puede apreciar, cuyo espíritu refleja una situación muy alejada de la realidad penitenciaria de aquellos momentos. Tan burda era la manipulación que ni se hacía constar la identidad del autor y de sus familiares. Era exclusivamente propaganda, como también lo fue, en este caso en octubre

49. Cecilio nos facilitó su testimonio en 1989.

50. Este texto fue publicado en la prensa regional con el siguiente título: «Párrafo de una carta dirigida por un prisionero de guerra a un familiar", y constaba la siguiente coletilla en su introducción: "para que nuestros lectores conozcan qué trato se da a los prisioneros de guerra en la España Nacional (...)». Diario Extremadura, 26-XI-1937. 
de 1938, la celebración de la Fiesta del Caudillo, que el Gobernador Militar de Cáceres aprovechó para dar un rancho especial a los prisioneros de guerra del campo de concentración de la plaza de toros de Cáceres, y éstos, al parecer, contestaron con un escrito dirigido a los mandos de dicho campo en los siguientes términos:

«(...) Rogamos todos y elevamos fervorosas plegarias al Sumo Hacedor para que continúe iluminando a nuestro Generalísimo por el camino de la salvación de España Católica y que jamás consienta que en este suelo se claven las garras soviéticas $(\ldots))^{51}$.

Creemos que párrafos como el anterior se descalifican por sí solos y no procede efectuar más interpretación que la meramente propagandística, tan utilizada por ambos bandos a lo largo del conflicto armado.

\section{REDENCIÓN DE PENAS Y LIBERTAD CONDICIONAL}

El elevado número de prisioneros, que en toda la zona franquista ascendía, al 31 de julio de 1937, a la cifra de 44.441, total que se incrementó en meses sucesivos, de forma que la población penitenciaria al final de la guerra se calculaba en 100.242 presos, cifra que se duplicó en 1940 al alcanzar los $210.219^{52}$, planteó problemas de espacio y también de intendencia, especialmente por la carencia de recursos para poder mantenerlos. Dificultades materiales a las que ya se trató de hacer frente en 1937, con la aprobación de decretos como el de 28 de mayo de ese año, en cuya introducción se indicaba:

«El derecho al trabajo que tienen todos los españoles no ha de ser regateado por el Nuevo Estado a los prisioneros y presos rojos (...), lo que supone que puedan sustentarse con su propio esfuerzo, que presten el auxilio debido a su familia y que no constituyan un peso muerto al erario público "53.

Ese decreto abría a los presos la posibilidad de trabajar como peones, actividad por la que cobrarían un jornal de 2 pesetas diarias, de las cuales, 1,50 serían para su manutención y el resto para él, con la salvedad de que "en caso de tener familia en zona nacional percibiría 2 pesetas más para su mujer y 1 por cada hijo menor de quince años, con la opción de que cuando el prisionero desempeñara un trabajo distinto al de peón le sería aumentado el jornal». Esa posibilidad de trabajar y cobrar dinero constituía un aliciente para los presos, aunque sólo algunos van a poder gozar de ese status. Y es que dependiendo de la gravedad de las inculpaciones que hubiera sobre cada recluso, las autoridades franquistas determinaban quiénes tenían derecho a este sistema de trabajo. Un condicionamiento de primer orden, sin duda, al recaer sobre la mayoría de los presos republicanos importantes acusaciones, que impedían esa posibilidad de trabajar.

51. Diario Extremadura, 8-X-1938.

52. Berdugo, I. y otros, op. cit., p. 281.

53. Boletin Oficial de la Provincia de Cáceres, 5-VI-1937. 
Al año siguiente, el contenido de este decreto se completó con nuevas instrucciones, entre las que cabe destacar, en primer lugar, la orden de 7 de octubre de $1938^{54}$, por la que se creaba el ya citado Patronato Central para la Redención de Penas por el Trabajo ${ }^{55}$. Con ese fin se crearon destacamentos de trabajadores para ser empleados por empresas del Nuevo Estado y también privadas, bien entendido que sólo tendrían derecho a percepción de subsidio "los reclusos que estén legítimamente casados y los hijos que tengan la calidad de legítimos o naturales reconocidos ${ }^{56}$. Connotaciones católicas en una iniciativa que para autores como I. Berdugo merece la siguiente calificación:

"Encubierto en un retribucionismo de tintes religiosos "el preso ha pecado $y$ redime su pecado con el trabajo", se facilita la reconstrucción del país y se soluciona el grave problema de mantenimiento de una población reclusa muy abundante. Se utiliza mano de obra barata en beneficio del Estado que, a cambio, reduce su condena; en principio un día por cada dos de trabajo y, posteriormente, llega a obtener, también, la libertad condicional, ${ }^{57}$.

Respecto a la obtención de libertad, fue necesario esperar al decreto de 9 de junio de $1939^{58}$, que en su introducción hacía constar: "Ninguna fórmula más sencilla y eficaz para conectar la redención de penas por el trabajo que la aplicación de la libertad condicional, obteniendo el recluso la doble ventaja de revisar periódicamente su condena y de quedar en libertad». Por tanto, rebajaban el tiempo de pena y se abría la posibilidad de quedar libre. Esto último, hasta entonces competencia de las Comisiones Provinciales de Libertad Condicional, según establecía el Reglamento de Prisiones, se había utilizado muy poco hasta entonces.

Por medio de ese decreto, el Patronato Central de Redención de Penas por el Trabajo ampliaba sus funciones, al asumir las de la mencionada Comisión, es decir, pasaba a controlar tanto las reducciones de penas como la concesión de libertad condicional ${ }^{59}$. Y lo cierto fue que, dentro del precario estado en que se encontraba la población reclusa, fruto de esas disposiciones bastantes presos se

54. Boletín Oficial del Estado, 11-X-1938.

55. Unas Juntas Locales dependientes del Patronato se encargarian de controlar todos los asuntos relacionados con la rebaja de condena por la vía del trabajo. Esas Juntas, compuestas por un representante del Ayuntamiento que necesariamente tenía que estar afiliado a Falange, un sacerdote y un vocal designado por el Patronato, organizaría el pago del subsidio a los familiares de los reclusos.

56. En esta orden se delimitaba, de acuerdo con la condena impuesta a cada recluso, el lugar donde podían trabajar éstos según el siguiente criterio: «en las penas de reclusión perpetua, sólo dentro del destacamento penal; los de temporal podrán hacerlo, además, en campos de concentración debidamente vigilados; mientras que los de menor gravedad accederían a un régimen de mayor libertad y en relación con obreros libres, si bien siempre debidamente vigilados».

57. BeRDUGO, I. y otros, op. cit., p. 282.

58. Boletín Oficial del Estado, 13-VI-1939.

59. Se encargarían los directores de prisiones de redactar los expedientes para la concesión de libertad condicional, y para ello debían tener en consideración el tiempo de la pena a condonar al recluso como consecuencia de su vida de trabajo, y extender su propuesta tanto a dicha condonación como a la aplicación de libertad condicional. 
vieron agraciados por las medidas, no sólo en lo referente a rebajar sus condenas, sino en la obtención de beneficios como la libertad condicional.

Ésta obligaba a los presos a permanecer en su localidad, con el compromiso de informar mensualmente a la prisión provincial, a través de su Ayuntamiento, tanto de su residencia habitual como de la actividad que desempeñaba. Un ejemplo de esos escritos, generalmente realizado por los funcionarios municipales, se expone a continuación:

"Amadeo Barba Carretero, vecino de Navatrasierra, en uso de la libertad condicional, informa al director de la prisión provincial que en el tiempo que lleva disfrutando la gracia concedida ha cumplido con su deber y consejos recibidos, estimando se porta bien. Trabaja todos los días, unas veces a jornal, ganando 6 pesetas, y otros haciendo carbón, ganando 7 pesetas, aunque sin hacer economía por los atrasos que hay en su casa. Navatrasierra, 1 de octubre de $1940{ }^{60}$.

Un estudio sobre la población reclusa que ingresó en la prisión provincial de Cáceres entre 1936-1939 y que resultó favorecida por la concesión de libertad condicional tras encontrarse cumpliendo condena de reclusión, muestra que el número de beneficiados por esa medida se situó en torno a los dos centenares. Y en la posguerra, fue en 1941 cuando se alcanzó la cifra más elevada con un total de 127 liberados, frente a los 60 de 1940. En el bienio 1942-1943, a consecuencia de indultos y otro tipo de iniciativas que pusieron en libertad a bastantes reclusos que habían ingresado durante la contienda, el número de los que alcanzaron libertad condicional se situó en 40 prisioneros.

Pero independientemente de esas cifras y de los beneficios inherentes a las medidas de política penitenciaria que se fueron aprobando con el transcurso de los años, la realidad fue que los efectos de la guerra sobre los vencidos, sobre los prisioneros republicanos que habían permanecido encarcelados durante años y ahora podían acceder a una situación de libertad condicional, no terminaban con el paso a ese grado, sino que continuaban estando presentes con posterioridad. Y es que su reinserción social se tornaba difícil y complicada al ser objeto de frecuentes rechazos por una sociedad embebida en el mundo de los vencedores de la Guerra Civil, que los consideraba desafectos y prefería vivir alejados de ellos. Afortunadamente, con el paso del tiempo esa imagen fue variando sustancialmente, y se fue produciendo, aunque con no pocas reservas, su paulatina aceptación.

60. APPCC, Exp. 1.485-41, Amadeo Barba Carretero. 